\title{
UNDERSTANDING WORK MOTIVATION FOR EMPLOYEES WORKING IN INFORMATION TECHNOLOGY INDUSTRY FROM HERZBERG'S PERSPECTIVE
}

\author{
Dr. Niraj Kishore Chimote \\ Associate Professor-HRM and OB \\ ICFAI Business School (IBS) Hyderabad, Telangana, India \\ Ashima Malhotra \\ Student of MBA: 2019-21 Batch, IBS Hyderabad, Telangana, India
}

\begin{abstract}
In the changing times, the source of employee motivation has become more and more dynamic. The HRs around the world are trying to tap the right causes for motivation to sustain employee engagement and enhance job satisfaction. This paper examines the various factors of job satisfaction and job dissatisfaction among IT sector employees using Herzberg's theory of motivation as underlying factors of motivation. This research is empirical in nature as it involves the administration of a questionnaire to the responses on the basis of their current job role in IT sector. The results indicated that the factors causing job satisfaction and job dissatisfaction differ in nature as explained by Herzberg. However, some factors like advancement, company policies and interpersonal relations showed mixed results towards their contribution to either job satisfaction or dissatisfaction.
\end{abstract}

Key words: Information Technology, job satisfaction, Motivation

Cite this Article: Niraj Kishore Chimote and Ashima Malhotra, Understanding Work Motivation for Employees Working in Information Technology Industry from Herzberg's Perspective, International Journal of Management, 11(12), 2020, pp. 955-981.

http://iaeme.com/Home/issue/IJM?Volume=11\&Issue=12

\section{INTRODUCTION}

Motivation is such a factor that exerts a driving force on our actions and work. Motivation as defined by the Merriam-Webster dictionary 11 th edition is " 1 a: the act or process of motivating $b$ : the condition of being motivated $2 \mathrm{a}$ : a motivating force, stimulus, or influence b: INCENTIVE, DRIVE". As indicated by Baron (1983), motivation is an aggregation of 
various procedures which impact and direct our conduct to accomplish some particular objective. The way that motivation is the most significant factor for efficiency and quality is certifiably not another disclosure. It has been brought up by the investigations led Elton Mayo around 1930. From that point forward there have been a few investigations that affirmed similar outcomes in a few businesses including software development one. It is such a dynamic in the present condition that unequivocally makes and incorporates a positive effect on work. Inside an organization, the best execution is possible with most dedicated representatives that can only be accomplished through worker motivation. Motivation relies upon certain natural, just as, extraneous elements which in joint effort brings about completely dedicated employees in an organization.

Various theories around the concept of motivation and how it can be employed in an organization so as to increase efficiency of employees then came into picture. The theories were then classified into 2 types: content theory and process theory. A content theory addresses the factors that determine motivation. A process theory, on the other hand, treats motivation as a process, and aims to identify how individuals will or should act to identify what their motivators are and to achieve the goals associated with these motivators. The main content theories are: Maslow's needs hierarchy, Alderfer's ERG theory, McClelland's achievement motivation and Herzberg's two-factor theory. On the contrary, the main process theories are: Skinner's reinforcement theory, Victor Vroom's expectancy theory, Adam's equity theory and Locke's goal setting theory.

As indicated by Herzberg's Two Factor Theory, there are factors that positively affect the expansion of motivation - the motivators, that Herzberg relates to the inherent factors; and different components that must be available so as to keep away from de- motivation, yet by themselves can't upsurge motivation-the Hygiene factors, that Herzberg relates to the outward factors. Corresponding to this theory, motivators derive from "that unique human characteristic, the ability to achieve and, through achievement, to experience psychological growth". They are, in order of importance, achievement, recognition, work itself, responsibility, advancement, and possibility for growth. In contrast, Hygiene factors are an outcome of mankind's creature nature and identify with the essential organic needs-for instance, the requirement for nourishment brings in cash a need. Some hygiene factors are organization arrangement, office space, supervision, individual life, and compensation.

Information Technology in India is an industry comprising of two significant segments: IT administrations and business process outsourcing (BPO). The segment has expanded its input to India's GDP from $1.2 \%$ in 1998 to $7.7 \%$ in 2017 and is expected to contribute $10 \%$ to India's GDP by 2025. According to NASSCOM, the segment amassed income of US\$160 billion in 2017, with export income remaining at US\$99 billion and local income at US\$48 billion, developing by over $13 \%$. The United States represents $66 \%$ of India's IT services exports.

This paper is aimed at understanding the factors acts as satisfiers and dissatisfiers in order to become a determinant of employee motivation for personnel working in the IT industry. It is segmented into three sections to explore in detail the understanding of Herzberg's theory as well as the trends in IT industry. The first Section deals with understanding the Herzberg theory of motivation and its related research as well as the ongoing trends in IT sector. The second section mentions about the process of collecting primary data, the methodologies applied as well as the concept used in the analysis of data. The third section involves the actual analysis of the data, the understanding of results and its implications in the IT industry. 


\section{LITERATURE REVIEW}

\subsection{Understanding Herzberg's Two Factor Theory}

Herzberg (1959) developed a two-dimensional worldview of factors influencing individuals' mentalities and attitudes about work. He reasoned that factors, for example, organizational policies, supervision, social relations, working conditions, and pay are hygiene factors instead of motivators. As indicated by this two-factor hypothesis, the nonappearance of hygiene factors can result in job dissatisfaction, however their presence doesn't rouse or create satisfaction. Conversely, he verified that the motivators were components that enhanced an individual's job; he discovered five factors specifically that were solid determiners of occupation fulfillment: accomplishment, acknowledgment, the work itself, obligation, and progression. Motivators allude to factors characteristic inside the work itself like the acknowledgment of a task completed. Then again, hygiene factors will in general incorporate extraneous variables, for example, relations with colleagues and supervisors, which don't relate to the person's real employment.

\section{HERZBERG'S TWO FACTOR THEORY}
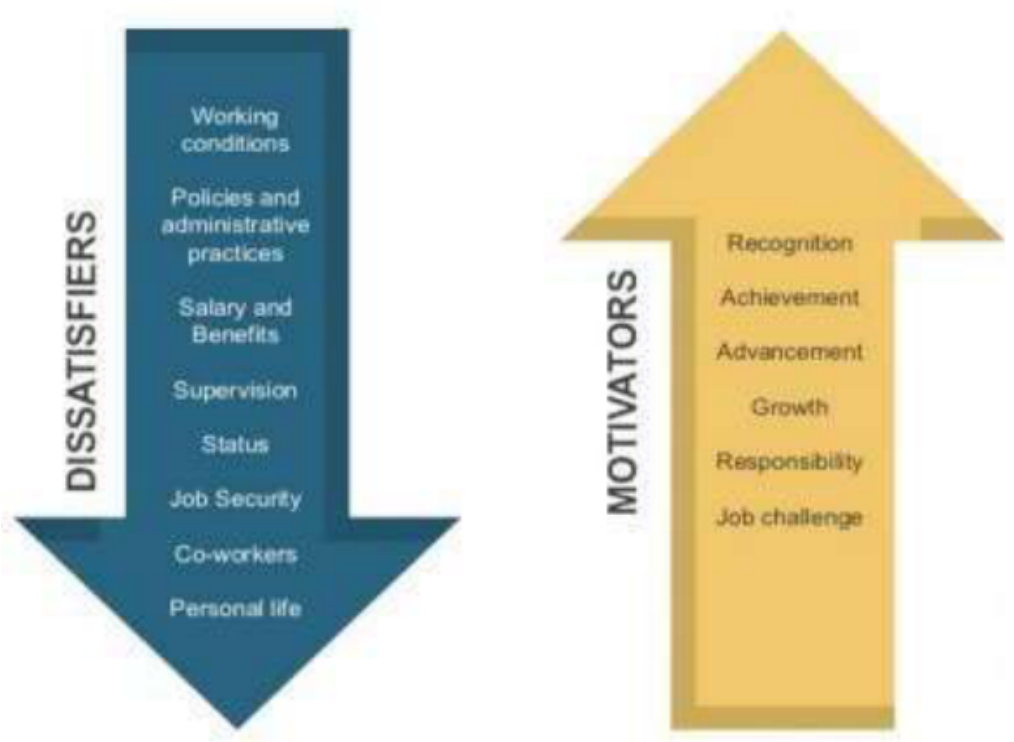

Figure 1

Source: www.slidemodel.com

These motivators (satisfiers) were related with long haul constructive outcomes in work execution while the hygiene factors (dissatisfiers) reliably delivered just momentary changes in work perspectives and execution, which immediately fell back to its past level. In synopsis, satisfiers depict an individual's relationship with what she or he does, many identified with the organizational tasks being performed. Dissatisfiers, then again, have to do with an individual's relationship to the specific circumstance or condition wherein she or he performs the job. In other words, the absence of motivators leads to no satisfaction and not dissatisfaction and similarly, the presence of hygiene factors leads to no satisfaction and not satisfaction itself. 


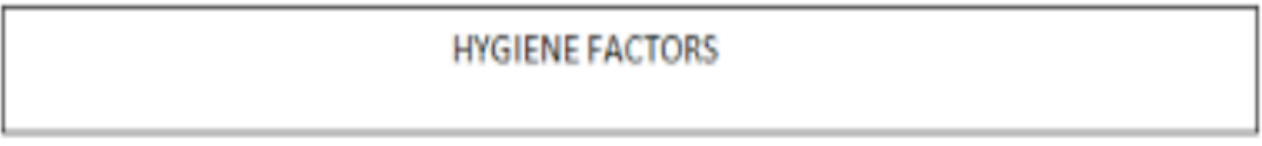

No Dissatisfaction

Dissatisfaction

Figure 2

Source: managementstudyguide.com

Herzberg's motivation-hygiene theory, also known as the two-factor theory has received widespread attention for contributing to a practical approach toward motivating employees. A study conducted by Negandhi (1985), in six African countries revealed that, workers in Africa and those of other countries in Europe and America, want not only wages and job security but also opportunities for advancement, fair treatment, better working conditions, challenging and interesting jobs, autonomy on the job and responsibility. Thus, the worker is also motivated by the motivator factors as postulated in Herzberg's theory. For most organizations teamwork and group cohesiveness have been seen to be essential for a conducive working environment and important in establishing positive workgroup relationships.

Lundberg and Andersson (2007) conducted a study to understand work motivation in a sample of seasonal workers at a tourism destination strongly steered by seasonality, situated in northern Sweden. A structural equations model tested Herzberg's Two- Factor Theory of work motivation empirically. The findings support Herzberg's Two Factor Theory and show that it still has validity as 'wage level' and 'rewards' load on hygiene factors, has a very weak and insignificant influence on work motivation. Out of the three manifest variables, 'meeting new people' loads strongest that further plays down the importance of monetary rewards to explain work motivation.

The theory has been disparaged on for several reasons: first, that it is procedurally constrained; Vroom (1964) has argued that the storytelling critical-incident method, in which the interviewee recounts extremely satisfying and dissatisfying job events, accounts for the associations found by Herzberg et al. and that other methods are required to adequately test the theory. Second it is also argued that the research from which it was inferred is fraught with procedural deficiencies; and third that it is inconsistent with past evidence concerning satisfaction and motivation. Brayfield and Crockett (1955) presumed that one's position with regards to his/her relationship with co-workers need not suggest solid motivation for exceptional performance inside the organizational framework, and that efficiency may just be incidentally identified with a large number of the objectives toward which the worker is striving. Herzberg's unique investigation has likewise been condemned on the grounds that it contains no proportion of in general fulfillment or overall satisfaction (Ewen, 1964). However, such a measure is important if a factor is to be called a satisfier or dissatisfier. There is no basis for assuming that the factors described as hygiene or motivators contribute to respondent overall satisfaction or dissatisfaction. Smith and Kendall (1963) have shown that a worker may dislike some aspects of his job, yet still think it is acceptable. Similarly, workers may dislike 
the job despite many desirable characteristics. Moreover, this theory also doesn't work in every cultural set up and fails to work when used without the critical incident technique.

The groundwork of two-factor theory is built on the factors for employees' job satisfactions. According to Spector (1997), job satisfaction can be defined as "the extent to which people like (satisfaction) or dislike (dissatisfaction) their jobs". Prior specialists have secured that job satisfaction is related with remuneration, word related pressure, empowerment, organization and administrative principles, accomplishment, individual development, relationship with others, and the general working condition (Teck-Hong and Waheed, 2011). Herzberg's theory has been used to study job-satisfaction of employees in different settings. For example, Purohit and Bandyopadhyay (2014) studied the driving factors of motivation for government doctors in India. After studying 92 doctors from three states in India, they found that the doctors placed significantly more motivational importance to intrinsic factors than to extrinsic factors. The study results indicated that job security was the most important factor related to motivation, which was closely followed by interesting work and respect and recognition. Their results coincided with the findings put forth by Herzberg.

However, contradictory evidence also exists. Ghazi and colleagues (2013) using Herzberg's two- factor theory tried to find out the job satisfaction and motivational level of university teachers in Khyber Pukhtunkhwa (Pakistan). Results revealed that university teachers were satisfied with both hygiene and motivator factors while university teachers' motivation is more dependent on the fulfillment of hygiene factors. It was concluded that for the university teachers, the fulfilment of hygiene factors itself acted as a catalyst for job satisfaction.

Another research proof exists in the form of research conducted by Chirarak Sithipand (1983) in which he used Herzberg's Two Factor Theory as a basis to understand Motivator as well as Hygiene Factors of employee working in commercial banks of Thailand. The results depicted a significant difference in the factors that act as satisfiers and dissatisfiers for an employee. The research further aimed to understand motivating and hygiene factors on the basis of gender and designation.

There are several theories other than that of Herzberg that have influenced the way organizations manage employees to achieve a motivated work force. These theories attempt to explain why people behave the way they do and advice on factors and strategies which when employed can get the best out of employees in terms of their commitment to work.

The principles of Herzberg Theory are often understood in comparison to Maslow's Hierarchy of Needs Theory to understand what motivates people in different human stages. Herzberg formulated his two-factor theory of motivation in 1959. This was followed by David McClelland's three needs theory (1961) wherein he proposed a motivational model which attempts to explain how the needs for achievement, power, and affiliation affect the actions of people from a managerial context. In 1964, Vroom put forth his expectancy motivation theory. The theory states that behavior results from conscious choices among alternatives whose purpose it is to maximize pleasure and to minimize pain. The variables used by him were expectancy, instrumentality and valence. Then came Alderfer's ERG needs theory of motivation (1969) which focused on Existence (fulfilling basic needs), Relatedness (fulfilling social needs) and Growth (reaching full potential) of an individual.

\subsection{Understanding IT Industry of India}

India is the world's biggest sourcing station, representing around 55 percent of the US\$ 185 190 billion market in 2017-18. India's exceptionally qualified ability pool of technically sound youth is one of the biggest on the planet and the nation has a minimal-cost advantage by being 5-6 times inexpensive than US. India is the second-quickest digitizing economy among 
17 driving economies of the world. India's IT industry has contributed to around 7.7 percent to the nation's GDP and is further expected to hold a share of 10 percent of India's GDP by 2025 .

The market size of IT-BPM division in India remained at US\$177 billion as of 2019 witnessing a development of 6.1 percent year-on-year and is expected that the size of the industry will develop to US\$ 350 billion by 2025 . Besides, income from the digital fragment itself is estimated to frame 38 percent of the total industry income by 2025 by which time the digital economy is assessed to arrive at Rs 69,89,000 crore (US\$ 1 trillion). Exports from IT sector expanded to US\$ 137 billion in FY19 while household/local incomes (counting equipment) progressed to US\$ 44 billion. The IT business has likewise made more than 4 million direct employments and 12 million backhanded occupations in India. IT industry representatives 4.1 million individuals starting at 2019 itself.

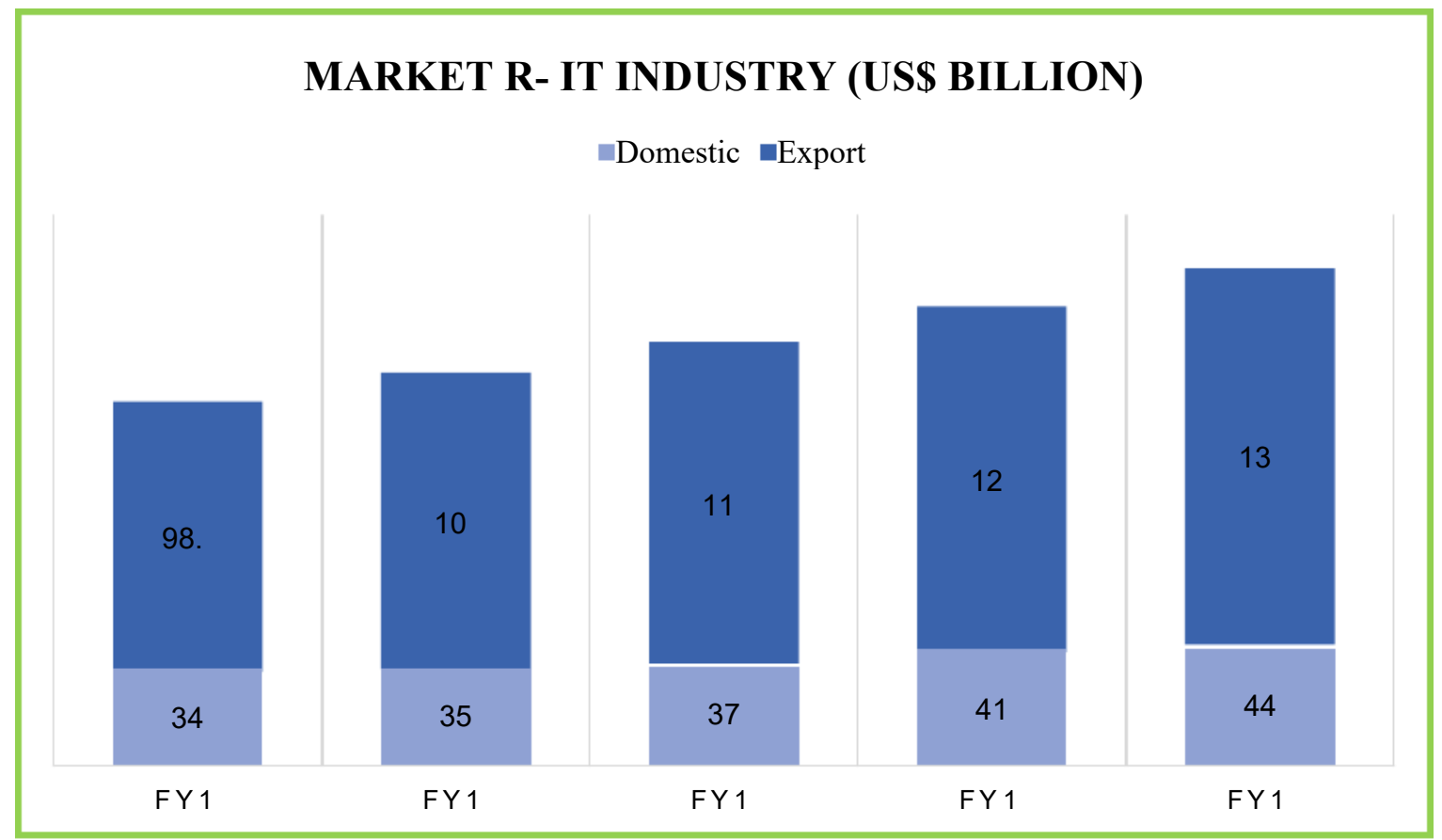

Figure 3

Source: ibef.org

Indian IT's center abilities and qualities have pulled in huge ventures from significant nations. The PC programming and equipment segment in India pulled in combined Foreign Direct Investment (FDI) inflows worth US\$ 39.47 billion between April 2000 and June 2019 and positions second in inflow of FDI, according to information discharged by the Department for Promotion of Industry and Internal Trade (DPIIT).

The Cloud benefits in India is evaluated to develop more than multiple times to Rs 49,621 crore (US\$ 7.1 billion) by 2022 with the help of Growing gathering of Big Data, examination, man-made brain power and Internet of Things (IoT), as demonstrated by Cloud Next Wave of Growth in report. Driving Indian IT firms like Infosys, Wipro, TCS and Tech Mahindra and so forth are broadening their contributions and exhibiting driving thoughts in blockchain, computerized reasoning to customers utilizing advancement center points, innovative work centres, so as to make separated contributions. 


\section{3. The role of motivation of employees in IT Industry}

In 2010, Sach et al. conducted a research on motivation of software practitioners which has been recognised as a key factor in system quality yet have a dearth of research on the same. In their research, the analysis was conducted on data collected from 23 current practitioners at a workshop on motivation aimed at investigating the motivational factors in current software practice. The methodology used was focused group discussion along with open ended questionnaire to further facilitate discussion. The sample was categorised among 3 groups, developers, technical managers and consultants. The result depicted that the most common factor of motivation was "people" for all the 3 groups followed by "problem solving" and "finance" as motivators for developers and technical managers while "challenging" acted as a motivator for consultants. The researched had strong implications for motivational programmes in software organisations, and paved way for the need for further empirical research in the area.

Motivation, although difficult to quantify, is considered to be the single largest factor in developer productivity; there are also suggestions that low motivation is an important factor in software development project failure. Verne et. al (2013) investigated factors that motivate software engineering teams using survey data collected from software engineering practitioners based in Australia, Chile, USA and Vietnam. They also investigated the relationship between team motivation and project outcome, identifying whether the country in which software engineering practitioners are based affects this relationship. Analysis of 333 questionnaires indicated that failed projects are associated with low team motivation. The result depicted a set of six common team motivational factors that appear to be culturally independent (project manager has good communication with project staff, project risks reassessed, controlled and managed during the project, customer has confidence in the project manager and the development team, the working environment is good, the team works well together, and the software engineer had a pleasant experience). Interestingly, the results also showcased unique groupings of team motivational factors for each of the countries investigated thereby, indicating that there are cultural differences that project managers need to consider when working in a global environment.

Anca Deak (2014) in her research attempted to understand the career paths of future software engineers looking for positions in the software industry who tend to lean towards software development/coding rather than software testing. The study investigated what factors cause software testing professionals working both in agile and traditional methodologies, to choose and remain in this career path. Using a qualitative survey among 6 software development companies, data was collected from 26 individuals with regards to the difference between the traditional and agile testers along with identification of motivating and demotivating factors in current testing practices. The results showed that motivating factors included new challenges, variety of work, recognition etc. while de-motivating factors included ack of influence and recognition, unhappiness with management, lack of organization etc. The results hoped to help the companies in their recruiting processes, in the transition from traditional to agile within a company and in motivating their testers, which will lead to better job satisfaction and productivity.

Farias Junior, Darte et al. (2012) presented an exploratory research on Distributed Software Development (DSD) and motivation. In the last decades, it was observed that major companies around the world started to use the strategy of Distributed Software Development (DSD) as a way of building competitive advantages. Aiming at the expansion of these advantages, many of these companies add some techniques for team motivation to the DSD thereby, increasing efficiency. The goal of research was raising and analyzing the key success factors for the motivation of dispersed teams. In the end, eleven success factors were collected 
and analyzed, and they were categorized according to a proposal that integrates concepts of the motivational theories of Maslow and Herzberg. The factors identified were nature of tasks, autonomy, feedback, creation of appropriate infrastructure, setting standards, perception of importance, sharing leadership, promoting team spirit, training, attention to cultural differences and attention to individualities and the results showed how the factors are related to different levels of motivation.

\section{HYPOTHESIS}

On the basis of thorough literature review for understanding Employee Motivation, Herzberg's Theory, Job Satisfaction and aspects of IT industry, following hypothesis has been developed.

Hypothesis 1- Among IT sector employees in India, there is no significant difference between job satisfaction and job dissatisfaction for the motivation factors.

Hypothesis 2- Among IT sector employees in India, there is no significant difference between job satisfaction and job dissatisfaction for hygiene factors.

Hypothesis for individual factors underlying motivation and hygiene factors will also be tested.

\section{METHODOLOGY}

Data Collection Procedure - Due to time constraints, convenience sampling was adopted and data was collected in the form of online surveys through social media handles and other online platforms. Before collecting the data, the participants accepted the declaration as to declaring their consent as well as maintenance of confidentiality of data by the researcher.

Data Collection Instrument - Data was collected through a close-ended questionnaire consisting of 90 items overall. The questionnaire was adopted from the research conducted by Ms. Chirarak Sithipand in his research on "Testing employee motivation based on Herzberg's motivation-hygiene theory in selected Thai Commercial Banks" in the year 1983. The questionnaire is divided into 3 parts:

- Demographic information

- Job satisfaction

- Job dissatisfaction

The odd-even reliability for instrument on job satisfaction for 0.93 and for job dissatisfaction instrument is 0.89 thereby, proving it to be a reliable test.

Sample Characteristics - The participants of the study include 35 individuals of the age 2130 working in IT sector across any location in India. There are 14 females and 21 males in the sample.

Data analysis Procedure - The data collected through questionnaires will then be coded in accordance with the 15 Motivators and Hygiene factors developed by Herzberg which are:

\section{Motivation Categories}

- Achievement

- Recognition Advancement Work Itself

- Possibility of Growth Responsibility

\section{Hygiene Categories}

- Company Policy and Administration

- Supervision-Technical 
- Interpersonal Relations-Supervisor

- Interpersonal Relations-Peers

- Salary

- Job Security

- Personal Life

- Working Conditions Status

The devised hypothesis is then tested through One Way Analysis of Variance. Analysis of variance (ANOVA) is an analysis tool used in statistics that splits an observed aggregate variability found inside a data set into two parts: systematic factors and random factors. The systematic factors have a statistical influence on the given data set, while the random factors do not. Analysts use the ANOVA test to determine the influence that independent variables have on the dependent variable in a regression study.

The ANOVA test allows a comparison of more than two groups at the same time to determine whether a relationship exists between them. The result of the ANOVA formula, the F statistic (also called the F-ratio), allows for the analysis of multiple groups of data to determine the variability between samples and within samples. Here, the satisfaction responses and dissatisfaction which are coded into 16 factors of Motivators and Hygiene Factors acted as multiple groups which have been used to determine whether there is a significant difference between factors underlying job satisfaction and job dissatisfaction or not.

\section{RESULTS AND DISCUSSION}

The present study is aimed at understanding the factors underlying motivation with regards to Herzberg's theory. The present study is aimed at testing hypothesis of significant difference between job satisfaction and job dissatisfaction with regards to both Motivation and Hygiene Factors using employees of IT industry as a sample.

Survey method was used for collection of data. A close-ended questionnaire with 100 items was used for the study. It was divided into 3 parts, demographic details, factors causing satisfaction and factors causing dissatisfaction. 43 responses were generated through convenience sampling out of which 35 were chosen to control extraneous variables like age, designation etc. so as to generate more concrete results. The responses were then coded into 6 motivating factors and 9 hygiene factors on which one-way analysis of variance was then applied to test the hypothesis.

The nature of data collected through this questionnaire was nominal. Nominal scale was chosen because of the sample which was very generalised in nature. The IT industry is a vast industry and includes sub-industries like IT services, Software as a Service, Business Process Management etc. and therefore, nominal data allowed to take a broad view of the factors that impact motivation of employees of this industry.

\section{DEMOGRAPHIC DATA}

\subsection{Age}

The age of the participants of the sample lies between 21 to 30 years of age. 


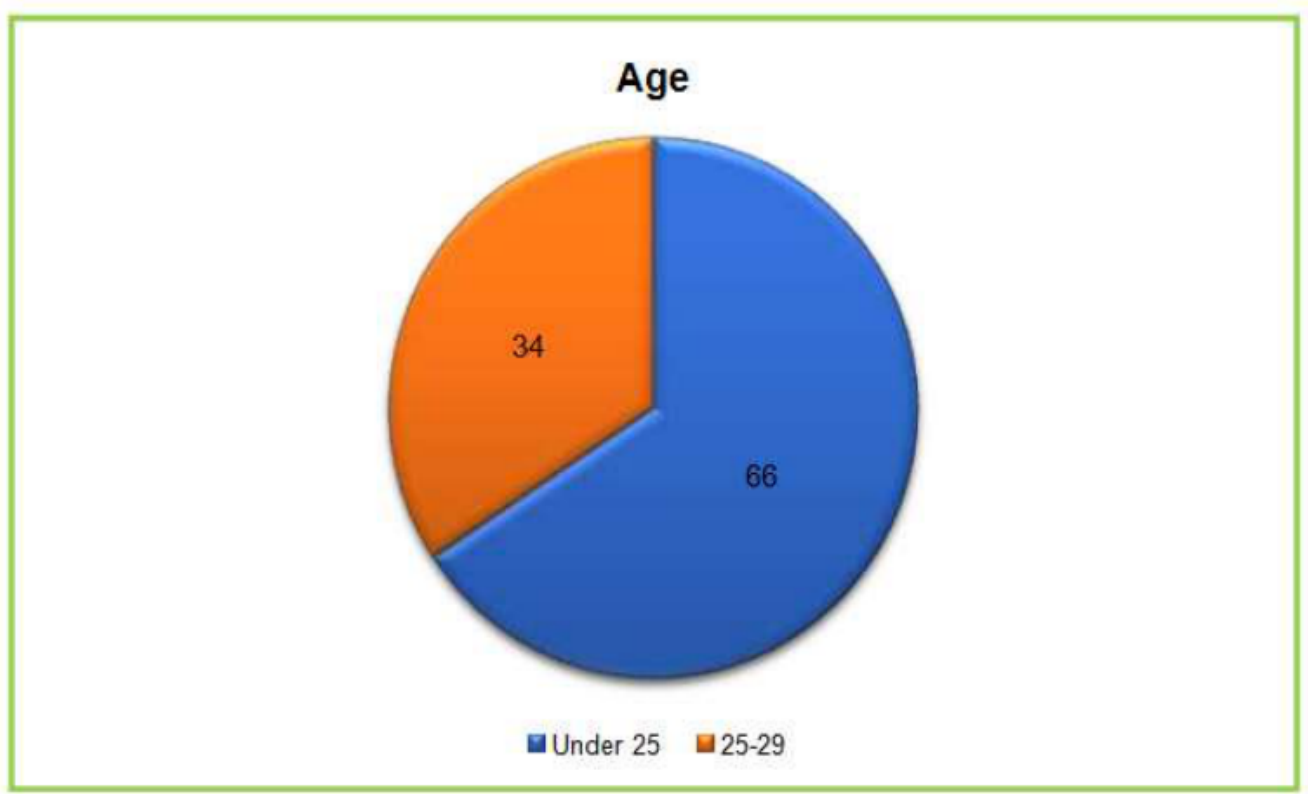

Figure 4

Out of 35 participants, 12 participants are under 25 years of age while 32 participants are around 25 to 29 years of age. The sample of this age allows to understand the motivation of employees that are relatively new to this dynamic industry. It is often concluded that with age, there is a general decline in motivation. However, a research conducted by Inceoglu et.al. (2012) in their findings concluded that older employees were less motivated by extrinsically but more by intrinsically - rewarding job features in contrast to younger employees.

\subsection{Gender}

The gender ratio of the sample is 60:40.

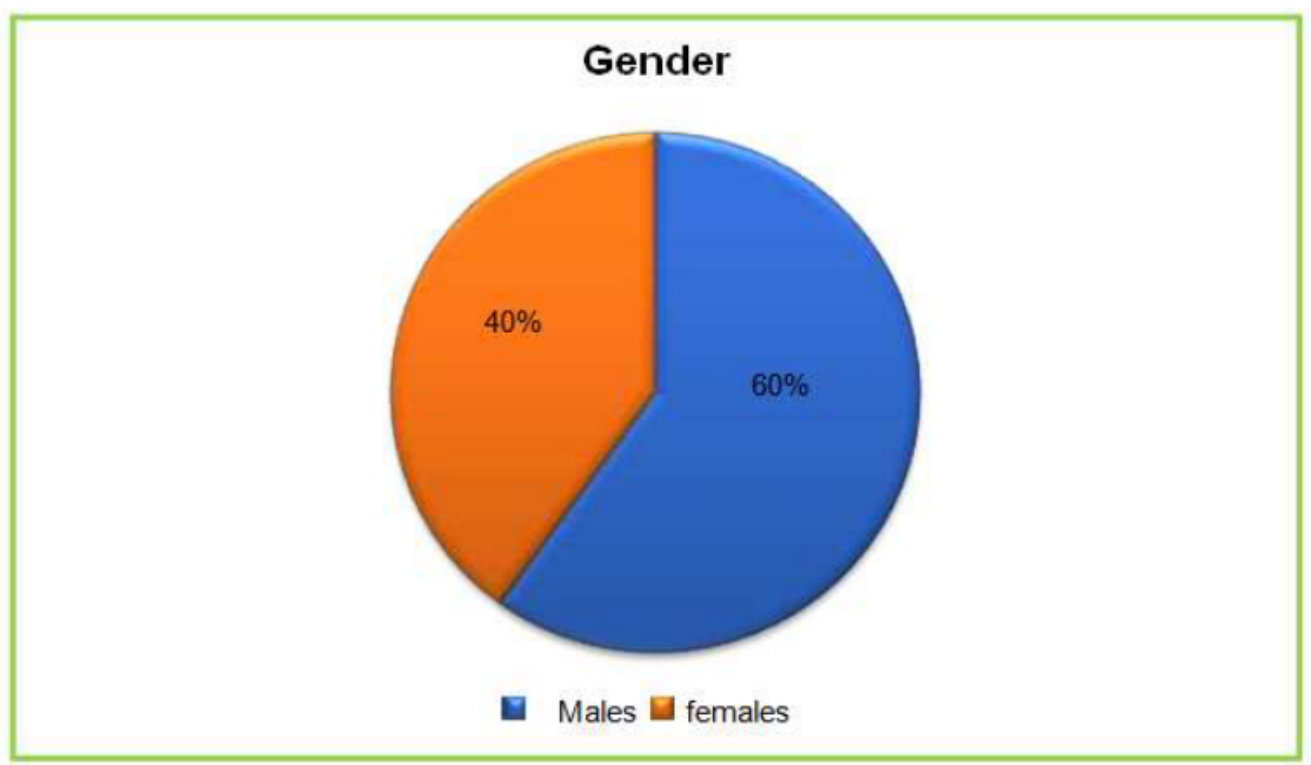

Figure 5

There are 14 females and 21 males that are part of the sample. Such a relatively equivalent sample neutralizes the role of gender in its impact as an extraneous variable on the results of 
the study. Mixed results have been found when it comes to understanding the impact of gender on motivation. (Veskova, Renata; 2006)

\subsection{Highest Level of Education}

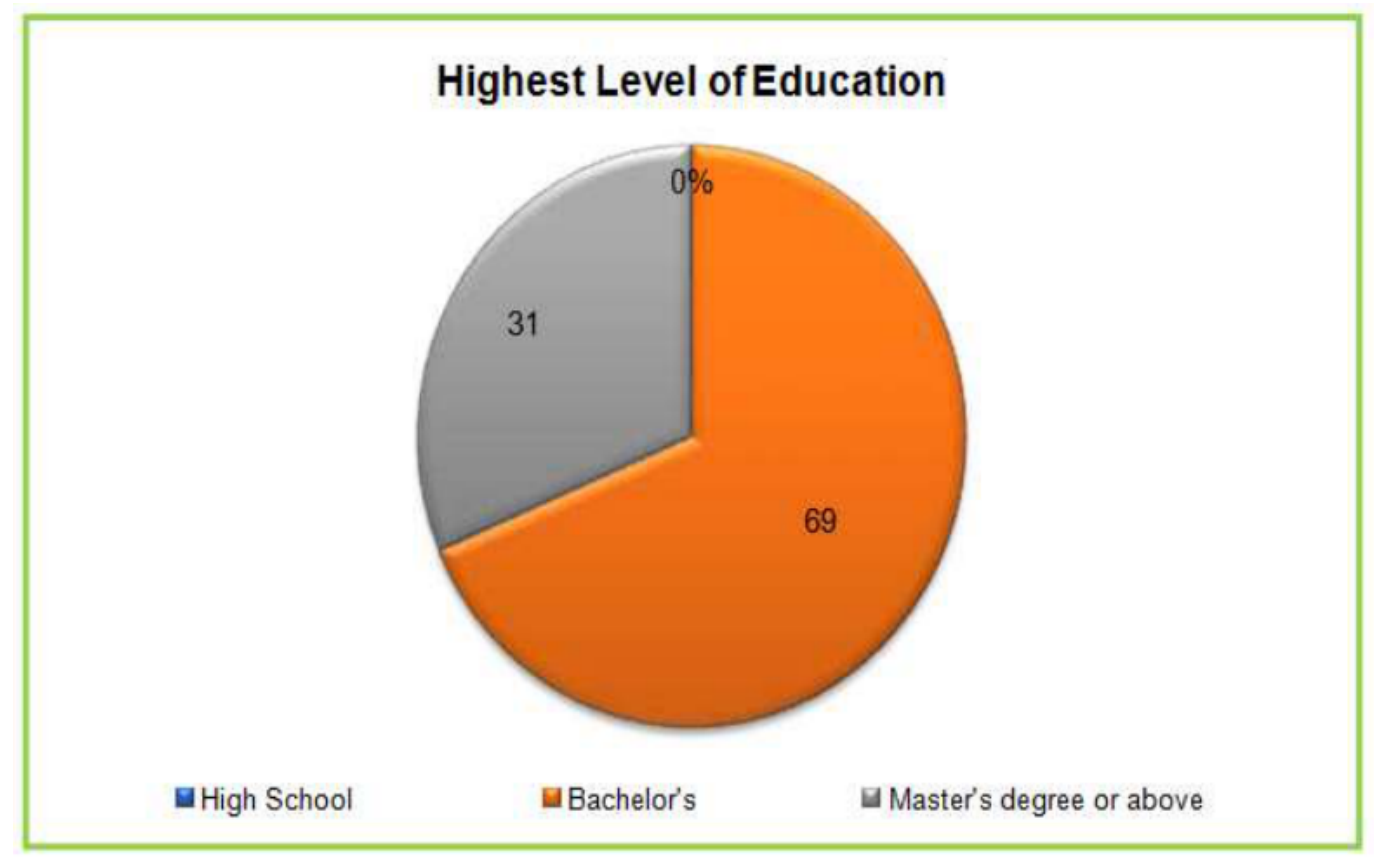

Figure 6

$31 \%$ of the participants have Master's degree or above while $69 \%$ of them have a Bachelor's degree.

\subsection{Tenure in the IT Industry}

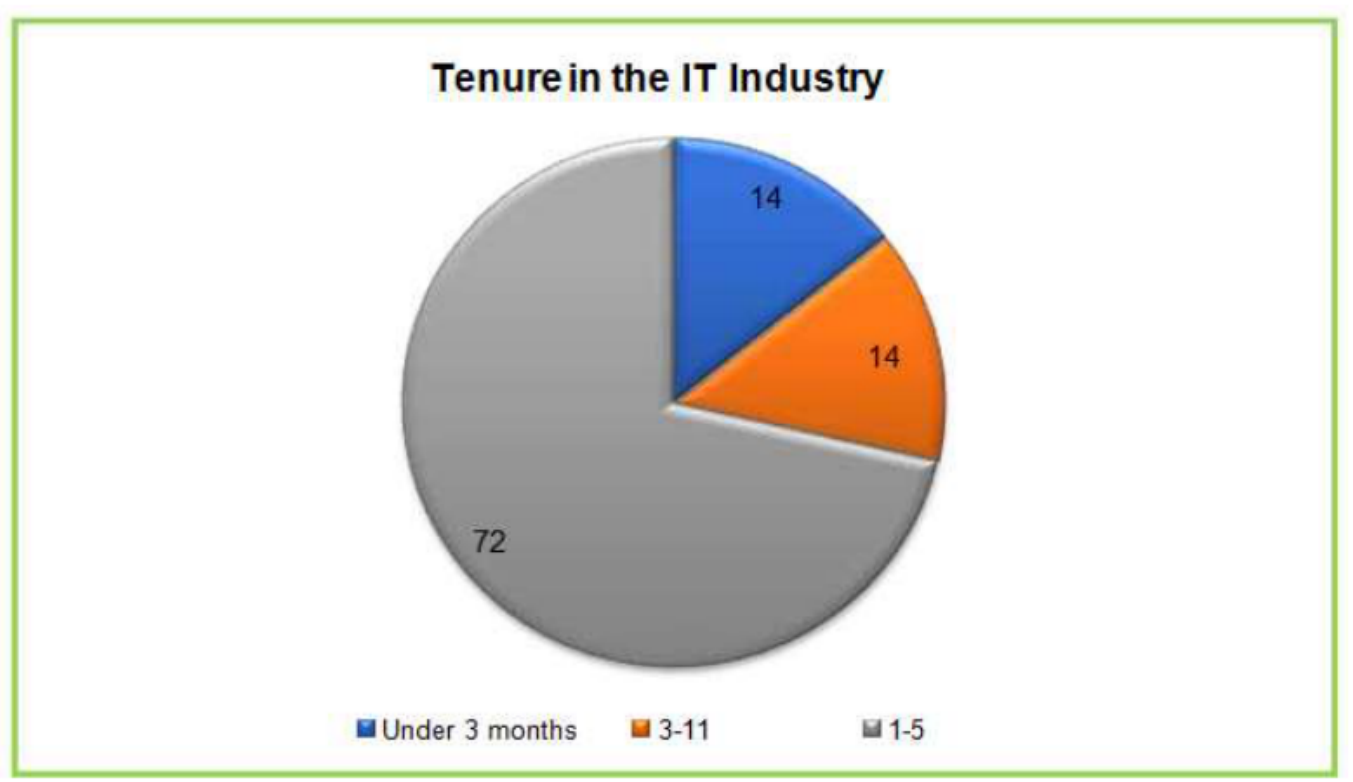

Figure 7

Since the participants are relatively young, the maximum work experience of participants is $1-5$ years $(72 \%)$ followed by $3-11$ months and under 3 months (both at $14 \%$ ). 
Understanding Work Motivation for Employees Working in Information Technology Industry from Herzberg's Perspective

\subsection{Frequency of Responses for Motivation Factor}

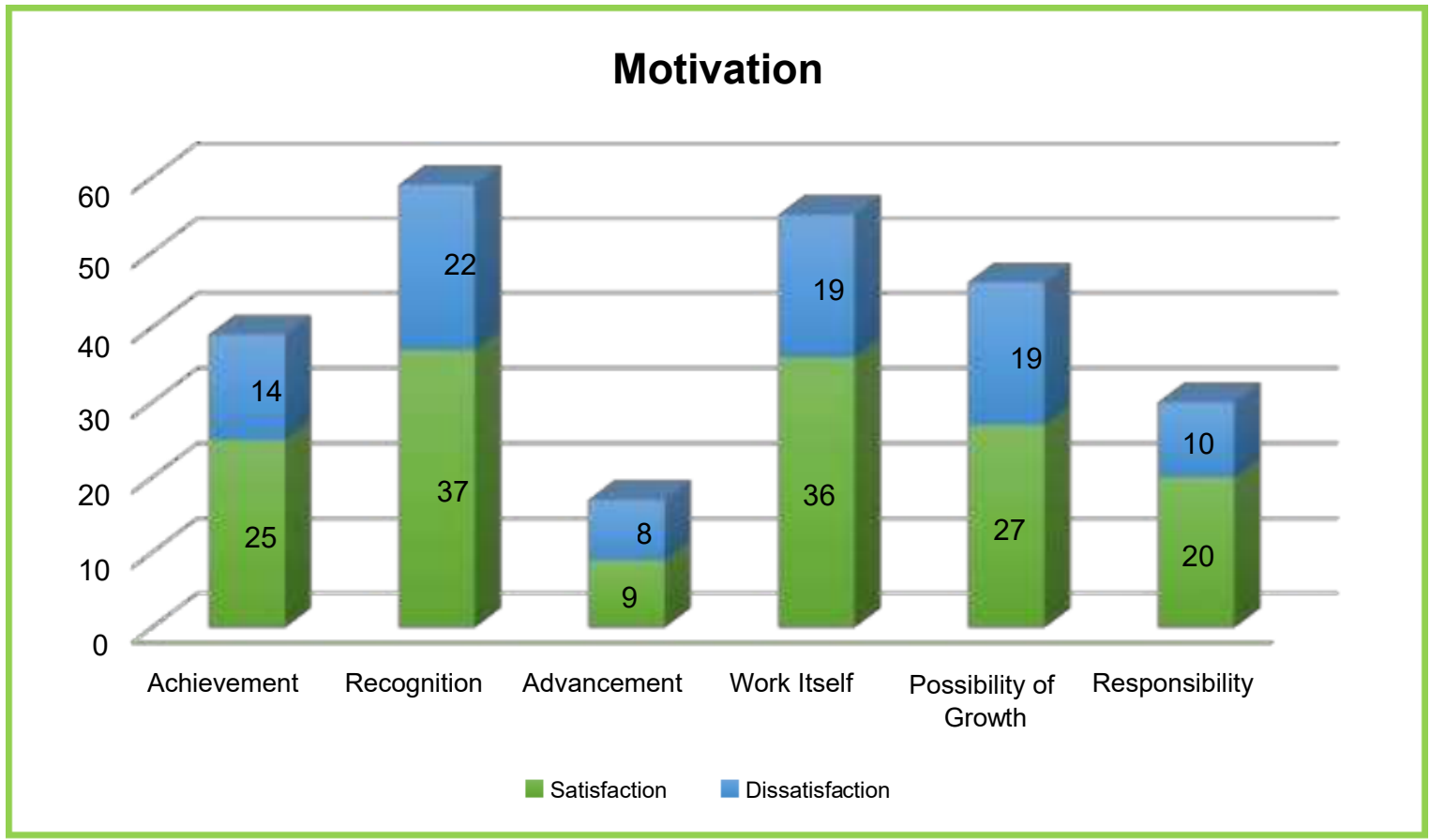

Figure 8

*the responses are more than the sample size because some variables have more than 1 item.

The result here depicts that recognition and work itself seems to be the most important factor in terms of satisfaction with maximum responses while advancement turned out to be the least important factor in terms of both satisfaction and dissatisfaction and had almost equivalent responses.

\subsection{Frequency of Responses for Hygiene Factors}

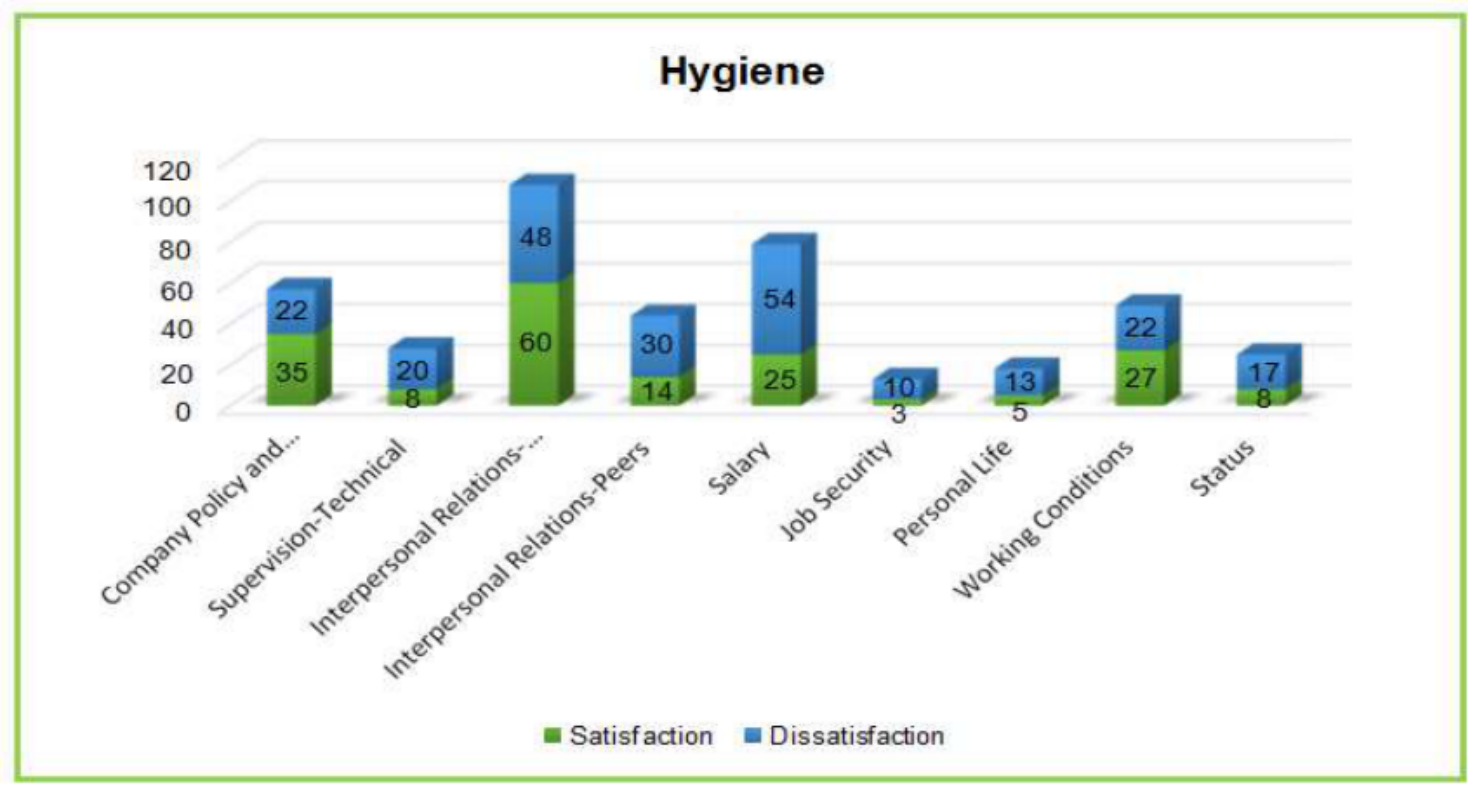

Figure 9

*the responses are more than the sample size because some variables have more than 1 item. 
From the table here, it can be deduced that salary is the most important component in terms of causing dissatisfaction while interpersonal relations with supervisor leans with more towards satisfaction side with 60 responses thereby, opposing Herzberg's theory and acting as a motivating factor.

\subsection{Feelings of Satisfaction}

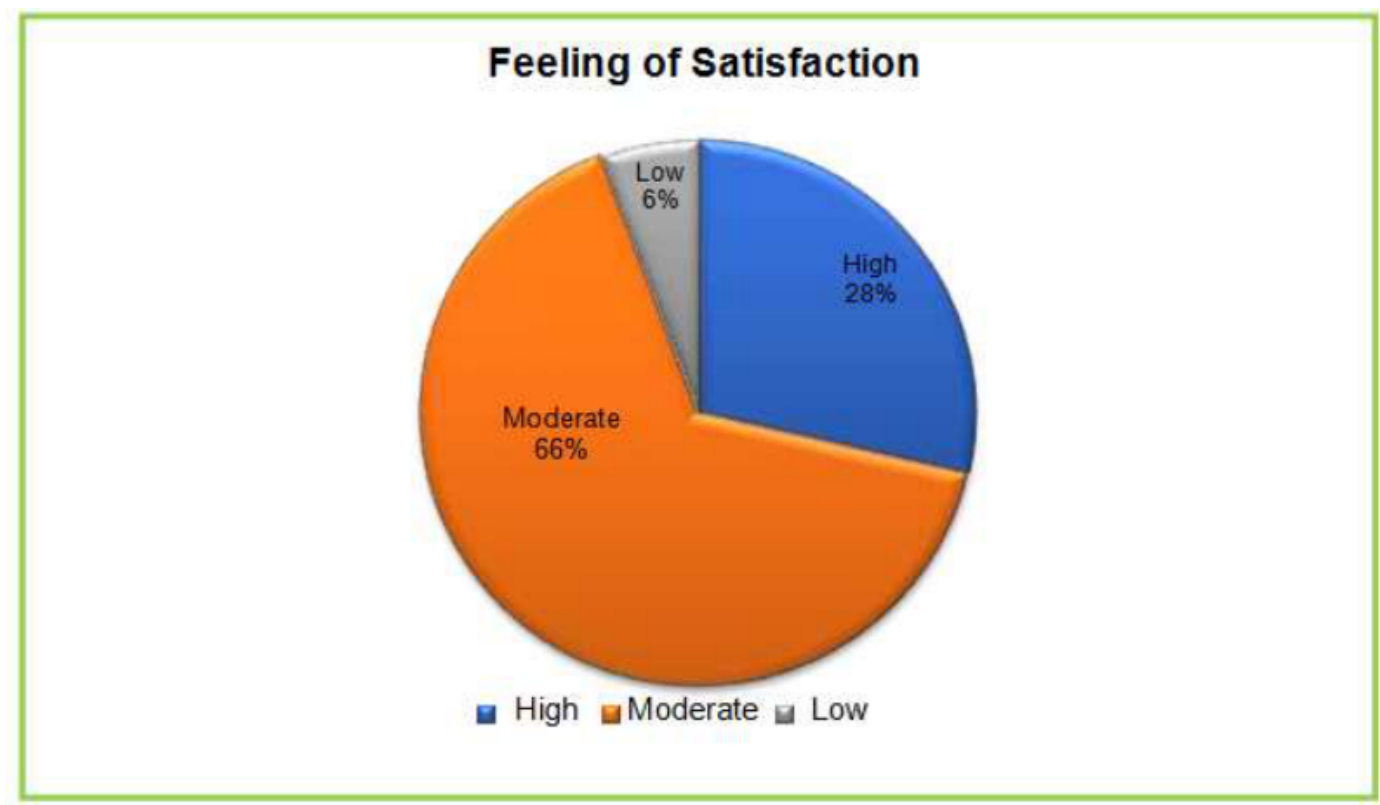

Figure 10

Majority of respondents $(66 \%)$ stated that had moderate level of satisfaction from their current employment while $28 \%$ stated to have high levels of satisfaction followed by only $6 \%$ participants stating low level of satisfaction.

\subsection{Feelings of Dissatisfaction}

$51 \%$ participants were moderately dissatisfied while $26 \%$ stated to have low levels of dissatisfaction and $23 \%$ were highly dissatisfied

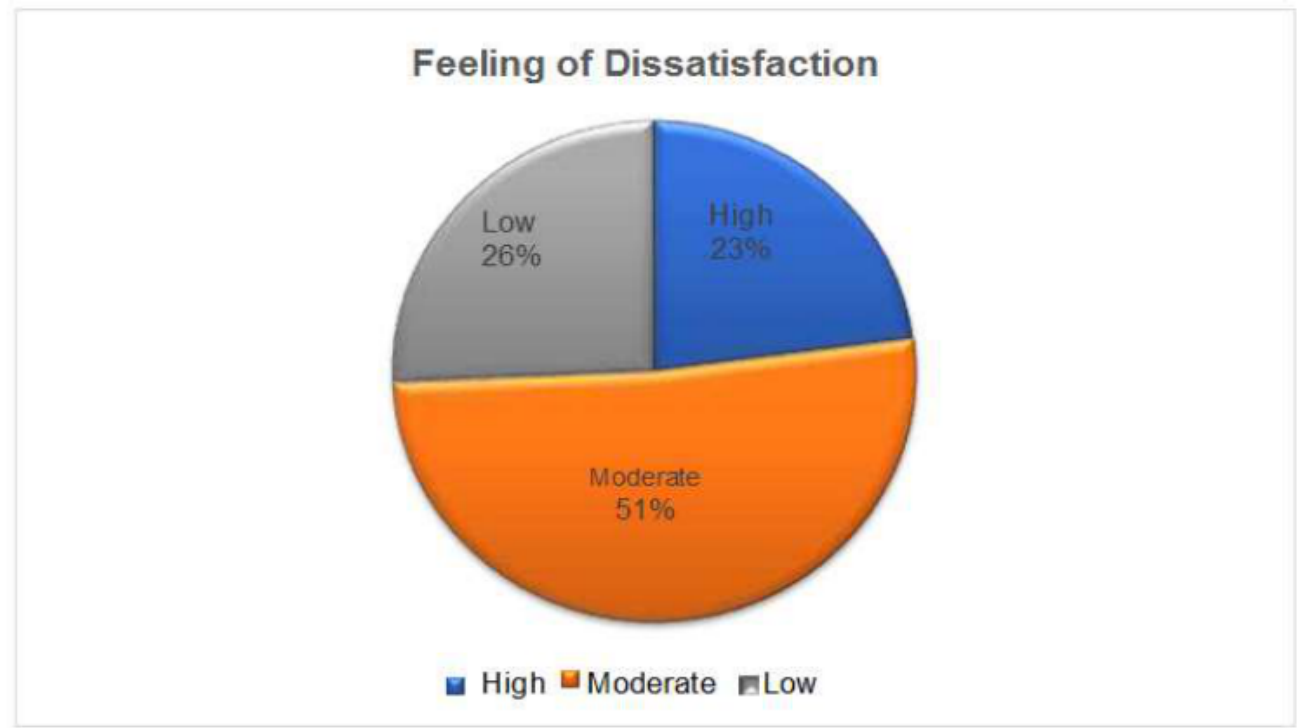

Figure 11 


\section{HYPOTHESIS TESTING}

\section{Hypothesis 1}

Ho- Among IT sector employees in India, there is no significant difference between job satisfaction and job dissatisfaction for the motivation factors.

HA- Among IT sector employees in India, there is a significant difference between job satisfaction and job dissatisfaction for the motivation factors

Table 1 ANOVA of Motivation Factor

\begin{tabular}{|l|c|c|c|c|c|}
\hline \multicolumn{7}{|c|}{ ANOVA } \\
\hline & $\begin{array}{c}\text { Sum of } \\
\text { Squares }\end{array}$ & df & $\begin{array}{c}\text { Mean } \\
\text { Square }\end{array}$ & F & Sig. \\
\hline $\begin{array}{l}\text { Between } \\
\text { Groups }\end{array}$ & 54.914 & 1 & 54.914 & 14.222 & .000 \\
\hline Within Groups & 262.571 & 68 & 3.861 & & \\
\hline Total & 317.486 & 69 & & & \\
\hline
\end{tabular}

At degree of freedom 1 (numerator) and 68 (denominator), with the confidence level at $0.05 \%$. The tabulated $F$ value is 3.68 which is less than the calculated $F$ value of 14.222 and therefore, the null hypothesis is rejected. There is a significant difference between job satisfaction and dissatisfaction in motivation factors. The support for the analysis can be found in the study conducted by Purohit and Bandyopadhyay (2014) studied the driving factors of motivation for government doctors in India. After studying 92 doctors from three states in India, they found that the doctors placed significantly more motivational importance to intrinsic factors than to extrinsic factors. The study results indicated that job security was the most important factor related to motivation, which was closely followed by interesting work and respect and recognition. Their results coincided with the findings put forth by Herzberg. (Table 1)

Apart from Hypothesis 1, analysis of variance was also done on factors underlying motivation so as to understand if there is any significant difference between satisfaction and dissatisfaction for each of the factors among IT sector employees

Table 2 ANOVA on Individual Factors Underlying Motivation

\begin{tabular}{|l|c|c|c|l|}
\hline \multicolumn{1}{|c|}{ Motivation factors } & $\begin{array}{c}\text { Satisfaction } \\
(\mathbf{n = 3 5})\end{array}$ & $\begin{array}{c}\text { Dissatisfaction } \\
(\mathbf{n = 3 5 )}\end{array}$ & F value & Result \\
\hline Achievement & 25 & 14 & 3.752 & Significant \\
\hline Recognition & 37 & 22 & 5.456 & Significant \\
\hline Advancement & 9 & 8 & 0.076 & $\begin{array}{l}\text { Not } \\
\text { significant }\end{array}$ \\
\hline Work Itself & 36 & 19 & 7.783 & Significant \\
\hline $\begin{array}{l}\text { Possibility of } \\
\text { Growth }\end{array}$ & 27 & 19 & 4.185 & Significant \\
\hline Responsibility & 20 & 10 & 6.182 & Significant \\
\hline
\end{tabular}

From the Table 2, it can be deduced that while advancement can be a factor that can result in both satisfaction and dissatisfaction among employees, the remaining 5 factors depict significant results and hence, have a more significant role to play as more of a motivating factor than hygiene factor as showcased through the high number of frequency.

\section{Achievement}

Achievement instills feelings of self-confidence, conviction and assertion in individuals and when these factors play out in work environment leads to high levels of motivation and 
thereby, job satisfaction. The table 5.2.2 depicts achievement to be a significant factor for motivation of employees in IT sector with the F value being 3.752 which is greater than the tabulated $\mathrm{F}$ value of 3.68 at $95 \%$ confidence level. Achievement is a strong motivation factor can also be inferred from the responses of employees with 25 employees selecting achievement response is satisfaction part of questionnaire while only 14 employees associated achievement or its lack thereof, with dissatisfaction. Beekhan, Anya (2012) conducted a study to investigate the relationship between achievement motivation and job satisfaction through a quantitative study. The effect of demographic data like age, race, gender and tenure was also examined on both achievement motivation and job satisfaction. Results showcased that there was a positive relationship between the dimensions of job satisfaction and the dimensions of achievement motivation. Achievement motivation was not significantly different between the categories of age, tenure and gender but showed a significant difference amongst race groups with African-Americans having the lowest mean score.

\section{Recognition}

Adler (2002; Adler \& Fagley, 2001) defined appreciation as acknowledging the value and meaning of something - an event, a person, a behavior, an object - and feeling a positive emotional connection to it. Experiences of appreciation enhance positive mood and feelings of connection to the appreciated stimulus and/or to the nature of existence (i.e., as in a feeling of awe or wonder). Recognition has both a normative and a psychological dimension. If one person recognizes another person with regard to a certain feature, as an autonomous agent, for example, the former does not only admit that that person has this feature but also embraces a positive attitude towards that person for having this feature. The analysis of the present data coincides with this study of Adler as with value 5.456 being greater than the tabulated $\mathrm{F}$ value. Since a significant difference has been proven for this factor, it can be safely presumed that recognition is one of the major factors resulting in increased job satisfaction and thereby, increased employee motivation with 37 responses being in favour of recognition as a source of satisfaction in contrast to 22 responses.

Appreciation and recognition can therefore, be a major factor in enhancing work confidence. Sometimes the positive feedback and response from supervisors, peers as well as customers motivates and positively reinforces a person to work. Reed (2000) found that employees reported increased work motivation when they felt their organizations recognised the hard work they put in and recognition was rated as the most important factor contributing to work motivation. Further, a paper by Tech Hong \& Waheed (2011) examined what motivates employees in the retail industry, and examines their level of job satisfaction, using Herzberg's hygiene factors and motivators. In this study, convenience sampling was used to select sales personnel from women's clothing stores in Bandar Sunway shopping mall in the state of Selangor. The results showed that hygiene factors were the dominant motivators of sales personnel job satisfaction. Working conditions were the most significant in motivating sales personnel. Recognition was second, followed by company policy and salary.

\section{Advancement}

Advancement and prospects for progression and promotion support more grounded work execution and stronger job performance since they position representatives to show exactly how well they can play out their occupations. The pattern of progression, inspiration, fulfillment and input are basic to job performance. However, the present study reflects a contradiction to the Herzberg theory as the results depict a no significant difference in terms of satisfaction and dissatisfaction of employees with regards to advancement as a factor of motivation. The calculated $F$ value of 0.076 is less than the tabulated $F$ value of 3.68 at $95 \%$ confidence level. The response to advancement as a source of job satisfaction or dissatisfaction 
was almost equivalent with 9 and 8 responses respectively. Therefore, it can be concluded that advancement can be a source for both satisfaction and dissatisfaction among IT industry employees.

A study conducted by Naveed, Usmaan and Bushra (2011) produced similar results where they investigated that whether promotion can predict job satisfaction or not in employees of glass industry in Lahore (Pakistan). Using A Likert-type with 156 participants, the results depicted that promotion has a modest and positive effect on job satisfaction. This clarifies that components like length of administration, capacity and abilities which are the determinants of advancement has moderate impact on upgrading the job satisfaction level of representatives.

\section{Work itself}

In the present study, nature of work was identified to be a motivating factor that emerged because Herzberg identified it to be one of the major factors in his theory. The positive feelings associated with nature of work results in creating a sense of meaningfulness, sense of competency, opportunities to learn and job opportunities among the employees. The results here depict a significant difference between satisfaction and dissatisfaction underlying the nature of work as a motivation factor with $F$ value (7.783) is greater than $F$ tabulated value. Over 36 responses were associated with work itself as a source of satisfaction while 19 responses were associated with dissatisfaction.

A person can draw a strong sense of meaningfulness from his/ her work which can come from various sources. Meaningfulness means "the value of a work goal or purpose, judged in relation to an individual's own ideas or standards" (May et al., 2004). Hackman and Oldham (1979) in their Job Characteristics Model mentioned how the job characteristic of task significance i.e. 'The degree to which the job has a substantial impact on the lives or work of other people, whether in the immediate organization or in the external environment.' Also creates a sense of meaningfulness in the employee which in turns, results in increase in motivation.

The nature of work also creates feelings of sense of competence in employees that can result in increased motivation towards work. According to Higher-Order Implicit Goals model by (Barrick and Mount, 2013), there is a sub-conscious goal called Achievement Striving which describes a person's need to demonstrate personal competence and a sense of accomplishment in the area of work. According to Herzberg (1959), work itself is an important aspect of motivating factors because the latter is linked to employee motivation and arise from intrinsic, or dependent, conditions of the job itself and thereby, result in job satisfaction. The data depicts that nature of work should be meaningful, varied and challenging for the employee to perform and to get motivated and organisations work a great deal to make this happen.

\section{Possibility of Growth}

Organizations nowadays support the growth of their employees by creating a management culture that encourages communication and training. Managers and employees need to form an interdependent relation so that employees can seek while managers can impart new skills and knowledge for a long-term growth of the organization. The upskilling and training allow both individual and organization development and has a holistic impact on both. In the present study, a significant difference is found $\left(\mathrm{F}\right.$ value $=4.185>\mathrm{F}_{\mathrm{tab}}=3.68$ ) between satisfaction and dissatisfaction with regards to possibility of growth as a factor of motivation. With 27 responses in support of growth as a source of satisfaction while 19 in contrast points to the opinion that growth results in job satisfaction. The said result is supported by the study Kaur and Kumar (2019) who attempted to examine the relationship and impact of training and 
development practices on job satisfaction of employees. Sample of the study was 360 and was limited to faculty members employed at institutes providing technical education in the city of Nagpur, Maharashtra, India. The research attempted to explore causality among variables. The results showed a strong relationship between training and development practices and job satisfaction among the faculty members of technical educational institutes. The study not only provided empirical credence to the importance of training and development practices but also suggestions regarding how educational foundations should direct a legitimate preparing need investigation to guarantee that fitting training and development practices are embraced. This would then lead to creating a learning environment in the organization which eventually contributes towards job satisfaction of employees through appropriate skills development for individual and organizational growth.

\section{Responsibility}

Autonomy is a personality trait characterized by a focus on personal achievement independence, and a preference for solitude. Autonomy defined from human resource perspective also means a level of discretion granted to an employee. It is known to bring some sense of job satisfaction among the employees. Responsibility is a major dimension that comes under Autonomy. Just like the term suggests, it is the state or fact of having a duty to deal with something or of having control over someone. Just like how in an organization, a person who is autonomous is usually one who feels responsible and feels like he is in charge for his own as well as for the work of the others within his or her organization setting.

Herzberg's theory concentrates on the importance of internal job factors as motivating forces for employees. Removing some of the control management has over employees and increasing the accountability and responsibility they have over their work, which would in return increase employee autonomy. In the present study, responsibility has been identified as one of the factors underlying motivation because the response to responsibility as a source of satisfaction was $100 \%$ more than the response of the same as a source of dissatisfaction. The analysis of variance among the two in association with responsibility also showed a significant difference between satisfaction and dissatisfaction with $F$ value (6.182) being greater than the $\mathrm{F}$ tabulated value.

A study on Psychological ownership: a study of autonomy and the nature of its association with task commitment was carried out by Raynolds, P. Michael (1973) The study begins with an investigation designed to test the 2-factor theory developed by Herzberg and his coworkers. (Herzberg, Mausner and Snyderman 1959). The 2-factor theory (Motivator and Hygiene factors) is supported by the results, but only when certain opinions known to exist are suppressed. The process of identifying with work, of seeing a task as a part of oneself, is called in this study Psychological Ownership and becomes the focus of the main investigation. The data was collected using an interview with open- ended questions and scaled questionnaires. An association is demonstrated between Psychological Ownership and the Autonomy which the individual had in the task. These factors in turn, are shown to be related to feelings of Task Involvement. Autonomy is compared with a 'Sense of Achievement' as a source of Task Commitment and found to be a more important factor in determining positive attitudes to a task than is reflected in managers' beliefs about what motivates their subordinates.

\section{Hypothesis 2}

Ho- Among IT sector employees in India, there is no significant difference between job satisfaction and job dissatisfaction for hygiene factors.

HA- Among IT sector employees in India, there is a significant difference between job satisfaction and job dissatisfaction for hygiene factors. 
Table 3 ANOVA for Hygiene Factors

\begin{tabular}{|l|c|c|c|c|c|}
\hline \multicolumn{7}{|c|}{ ANOVA } \\
\hline & $\begin{array}{c}\text { Sum of } \\
\text { Squares }\end{array}$ & df & $\begin{array}{c}\text { Mean } \\
\text { Square }\end{array}$ & F & Sig. \\
\hline $\begin{array}{l}\text { Between } \\
\text { Groups }\end{array}$ & 37.157 & 1 & 37.157 & 4.024 & .049 \\
\hline Within Groups & 627.829 & 68 & 9.233 & & \\
\hline Total & 664.986 & 69 & & & \\
\hline
\end{tabular}

At degree of freedom 1 (numerator) and 68 (denominator), with the confidence level at $0.05 \%$. The tabulated $F$ value is 3.68 which is less than the calculated $F$ value of 4.024 and therefore, the null hypothesis is rejected. There is a significant difference between job satisfaction and dissatisfaction in hygiene factors. The proof for the same can be found in Lundberg and Andersson (2007) study that aimed to understand work motivation in a sample of seasonal workers at a tourism destination strongly steered by seasonality, situated in northern Sweden. A structural equations model tested Herzberg's Two-Factor Theory of work motivation empirically. The findings support Herzberg's Two Factor Theory and show that it still has validity as 'wage level' and 'rewards' load on hygiene factors, has a very weak and insignificant influence on work motivation.

Table 4 ANOVA on Individual Factors Underlying Hygiene Factors

\begin{tabular}{|l|c|c|c|l|}
\hline \multicolumn{1}{|c|}{ Factor } & $\begin{array}{c}\text { Satisfaction } \\
(\mathbf{n = 3 5 )}\end{array}$ & $\begin{array}{c}\text { Dissatisfaction } \\
(\mathbf{n = 3 5 )}\end{array}$ & F value & \multicolumn{1}{|c|}{ Result } \\
\hline $\begin{array}{l}\text { Company Policy and } \\
\text { Administration }\end{array}$ & 35 & 22 & 3.556 & Not significant \\
\hline Supervision-Technical & 8 & 20 & 5.654 & Significant \\
\hline $\begin{array}{l}\text { Interpersonal Relations- } \\
\text { Supervisor }\end{array}$ & 60 & 48 & 1.304 & Not Significant \\
\hline $\begin{array}{l}\text { Interpersonal Relations- } \\
\text { Peers }\end{array}$ & 14 & 30 & 8.104 & Significant \\
\hline Salary & 25 & 54 & 15.763 & Significant \\
\hline Job Security & 3 & 10 & 4.815 & Significant \\
\hline Personal Life & 5 & 13 & 4.991 & Significant \\
\hline Working Conditions & 27 & 22 & 3.189 & Not significant \\
\hline Status & 8 & 17 & 5.276 & Significant \\
\hline
\end{tabular}

From the table, it can be deduced that company policies, interpersonal relations with supervisors and working conditions may also act as factors of motivation as the result of one way analysis of variance at 0.05 is less than the tabulated $F$ value of 3.68. Apart from these three, all have shown significant results.

\section{Company Policy and Administration}

Dissatisfactory company policies was identified as one of the factors leading to negative experience among the employees of IT Industry, dissatisfactory company policies leads to lethargy in work, feeling of demotivation and lack of acknowledgment, always experiencing dissonance at work, all of which leads to reduced levels of performance and employee absenteeism having serious repercussions on the company. The present study reveals that the responses towards company policy was more towards satisfaction levels with 35 responses in contrast to dissatisfaction with 22 responses. The $\mathrm{F}$ value of 3.556 is also less than the tabulated $\mathrm{F}$ value of 3.68. thereby proving that there is no significant difference in job satisfaction and job dissatisfaction among IT employees with regards to company policies and administration. The results therefore are in sharp contrast to what Herzberg suggested that 
company policies are only a source of reducing dissatisfaction but not a factor underlying employee motivation.

Several studies show a direct relationship between dissatisfactory company policies and performance levels. If the company policies are not in favour of the employees it leads to lower performance and vice versa. It has been concluded that worker dissatisfaction is one of the major concerns of every manager in the private sector and that strategic methods should be used when drafting company policies, the results of the Herzberg's factor analysis indicated that there is a high destructive force associated with company policy. The exit and neglect are considered as the destructive factors because they encompass on performance variables such as productivity, absenteeism, turnover, etc. upon subjecting the workers to questioning using the questionnaire, it was discovered that when asked about effects of company policy, majority said that they will result to voice criterion by letting the authorities know their displeasure with the company policy. One of the major company policies that impact individuals is the reward system and benefits. A study conducted by Ali and Ahmed (2009) provided contradictory evidence to Herzberg's theory. This study highlighted "the impact of reward and recognition programs on employee's motivation and satisfaction" Quantitative analysis showed immense support for positive relationship between the reward and satisfaction.

\section{Supervision Technical}

A competent supervisor can reduce the feelings of dissatisfaction among employees as the latter can learn a great deal from him. A supervisor with expertise in his/her domain allows room for growth of both organization as well as employees. In the present study, a significant difference was found for supervision as a factor for job satisfaction or dissatisfaction with $\mathrm{F}=$ 5.564 being greater than the tabulated $\mathrm{F}$ thereby, rejecting the null hypothesis The results leaned on more on dissatisfaction side with 20 responses in contrast to 8 responses for satisfaction. The results correspond with the study conducted by Liu and Batt (2010) which examined the role of supervisors in improving employee performance through the use of coaching and group management practices. The research subjects were call center agents in highly standardized jobs, and the organizational context is one in which calls, or task assignments, are randomly distributed via automated technology, providing a quasiexperimental approach in a real-world context. Results show that the measure of training that a worker got every month anticipated objective performance improvement after some time. Additionally, employees showed better performance where their administrator stressed group assignments and group incentives and where innovation was increasingly robotized. However, in terms of the positive connection among training and performance was more grounded where directors utilized gathering incentives forces, where innovation was less computerized, and where technological changes were less regular.

\section{Interpersonal Relations-Supervisor}

Good and friendly relations with supervisor allows the employees to form strong bonds and result in being a source of motivation. In the present study, no significant difference have been found with regards to interpersonal relations with supervisor as a source of satisfaction or dissatisfaction $(\mathrm{F}=1.304)$. However, frequency of responses lean towards it being a source of satisfaction as indicated by 60 responses in contrast to 48 responses for dissatisfaction and therefore, does not coincide with Herzberg's study which considers good inter-personal relations with supervisor as a basis of reduced dissatisfaction. For example: Reich and Hershcovis (2011) in their literature review of "Interpersonal Relationships at Work" stated that in terms of formal (i.e., organizationally sanctioned) workplace relationships, leaders that are perceived as "good listeners" have been associated with employee feelings of belonging, 
inclusion, social significance, and togetherness. In addition, positive interpersonal relationships with mentors have been associated with improved work-related outcomes, such as increased salary, organizational promotion, recognition, rewards, and an opportunity to establish a base of power. When organizations promote positive interpersonal relationships, others tend to follow the example, further creating a community of belonging (e.g., Baker \& Dutton, 2007).

\section{Interpersonal Relationship-Peers}

Interpersonal relationship with peers results in reduction of dissatisfaction among employees as this makes room for employees to partake in some event or activity that is not done keeping in mind benefit to the organization but for personal enjoyment. In the present study, the response towards interpersonal relationships with peers differed from the response of relations with supervisors. The participants responses showcase that good interpersonal relationship with peers is an underlying factor of reduced dissatisfaction but is not a major role player in increasing satisfaction i.e. in motivation factors. This is because significant difference has been found between satisfaction and dissatisfaction of interpersonal relationships with peers as a hygiene factor $(\mathrm{F}=8.104)$. The responses of participants depict that 30 responses were of interpersonal relations with peers and its association with dissatisfaction while 14 responses stated otherwise. However, contradictory evidence has been found in the literature review conducted Reich and Hershcovis (2011) that informal relationships (i.e., those that emerge without organizational involvement) were associated with positive work-related and personal outcomes. For example, attraction among co-workers enhanced teamwork, communication, and cooperation (Mainiero, 1989). Workplace friendships have been associated with numerous positive outcomes, such as increased job satisfaction, job involvement, job performance, team cohesion, organizational commitment, and decreased intentions to turnover. The benefits of positive interpersonal relationships for organizations are also manifold. For example, employee identification (i.e., one's adoption of the defining features of the organization as defining characteristics of oneself; Dutton, Dukerich, \& Harquail, 1994) has been related to increased employee compliance, motivation, job satisfaction, and group cohesion, as well as decreased turnover and in-group conflict (Kramer, 1991). In addition, Liden, Wayne, and Sparrowe (2000) found that positive interpersonal relationships were a key predictor of organizational commitment, and Kostova and Roth (2003) report that positive interpersonal relationships should be positively related to team performance, as they promote individual behaviors that are aimed at increasing team efficacy and efficiency.

\section{Salary}

Salary can go a long way in reducing the feelings of dissatisfaction among employees as it is one of the main reasons for which a person to partakes in employment activities. However, it does not mean that salary actually motivates people in doing their job. The results of the present study depict that there is a significant difference between satisfaction and dissatisfaction in employees as a result of salary. The calculated $\mathrm{F}$ value of 15.763 and 54 responses associated with dissatisfaction while 25 responses were in correspondence with salary as a source of satisfaction depicted how salary is one of the most important hygiene factor according to Herzberg. This has been proved through Judge and partners (2010) study in which they led a meta-analysis, thinking about the biggest measure of the examination on pay and its connection with job satisfaction. What they discovered was that pay level was barely identified with job satisfaction (.15) and a more significant compensation level doesn't really prompt more prominent job satisfaction. Furthermore, Williams, Mc Daniel and Nguyen (2006) found that pay level satisfaction just littly affects execution, 
scrutinizing the significance and adequacy of pay for performance scheme in general. Pay for performance's impact on inspiration of workers was looked into by Marsden and Richardson (1994) and was seen as preferably demotivating over propelling. The perception about high and low compensation level, just as the individual estimation of money is arbitrary. What was discovered by Judge and his colleagues (2010) was that bankers earning about 150.00 USD a year were not more satisfied than children care-takers earning 20.000 USD a year. Comparable models can be discovered all over logical research on compensation. Therefore, it can easily be concluded that salary does not lead to job satisfaction but only helps in prevention of job dissatisfaction.

\section{Job Security}

An unstable job or a job associated with feelings of uncertainty can surely go a long way in increasing job dissatisfaction. The results of the study reveal that there is a significant difference between job satisfaction and job dissatisfaction with regards to job security $(\mathrm{F}=$ 4.185). over 10 responses were associated job security with dissatisfaction while only 3 responses related job security with increasing satisfaction. A study was conducted by Shin et.al. (2019) to examine the relationship between job insecurity, intrinsic motivation, and performance and behavioral outcomes. Drawing on self-determination theory (SDT), they propose a mediated relationship in which job insecurity decreases intrinsic motivation, which, in turn, undermines job performance, organizational citizenship behavior (OCB), and changeoriented OCB. Data was collected through survey-based data from 152 R\&D professionals employed in a South Korean manufacturing company. As predicted, job insecurity was negatively related to intrinsic motivation, which, in turn, had a positive relationship with all three outcomes. Furthermore, job insecurity exerted significant indirect effects on job performance, $\mathrm{OCB}$, and change-oriented $\mathrm{OCB}$ through intrinsic motivation. These findings affirm SDT, which posits that motivation, as a key intermediary process, affects employees' reactions to job stressors.

\section{Personal Life}

No matter how much steps organizations take for employee engagement to keep them happy and motivated, the impact of factors of personal life cannot be fully done away with. Things like family problems, relocation, relationship issues etc. can have a huge impact on employee productivity and job dissatisfaction. The findings of the current study reveal that there is a significant difference between satisfaction and dissatisfaction in employees of IT sector as a result of their personal life. The $\mathrm{F}$ value $=4.991$ which is greater than tabulated $\mathrm{F}$ of 3.68 rejects the null hypothesis. 13 responses are in favour of personal life as a base of causing dissatisfaction among employees while 5 responses associate influence of personal life in bringing job satisfaction. Berman (2001) composed that as much as a business might not have any desire to be influenced by the individual existence of his employees, individual issues can once in a while influence the motivation of employees as well as their performance. Managers should be increasingly empathetic to personal problem of employees and be set up to talk about the issues with the employees when fundamental. On the off chance that a representative requires a break to manage an individual issue, Berman proceeded, at that point conceding that time off would assist with demonstrating every single other worker that the organization esteems its representatives. On the whole, motivation that prompts efficiency can be confounded.

\section{Working Conditions}

Work environment has a direct impact on employees. Work environment can improve employee performance and conversely, inadequate working environment can decrease 
employee performance. A good working environment where employees feel healthy, safe, and comfortable. Therefore, it is said that the determination and the creation of a good working environment will determine success in achieving organizational goals. The findings of the study revealed that there is no significant difference between satisfaction and dissatisfaction with regards to working conditions i.e. it can be a factor that can cause both satisfaction and dissatisfaction with $\mathrm{F}=3.189$. The responses are also more or less equivalent with 27 responses associating working conditions with satisfaction and 22 responses associating the former with dissatisfaction.

Therefore, in order to increase efficiency, effectiveness, productivity and job commitment of employees, the business must satisfy the needs of its employees by providing good working conditions. The objective of the paper by Raziq (2015) was to analyse the impact of working environment on employee job satisfaction. The study employed a quantitative methodology and a self-administered survey questionnaire. The target population consisted of educational institutes, banking sector and telecommunication industry operating in the city of Quetta, Pakistan. The outcomes demonstrated a positive connection between workplace and representative job satisfaction. The examination closed with some concise possibilities that the organizations need to understand the significance of good workplace for amplifying the degree of job satisfaction.

Another example can be sought through the research done by Agbozzo et. al (2017) who through their paper examined the impact of workplace on job satisfaction with the focus on a trader bank in Ghana. Among different targets, the paper set out to determine the effect of physical and mental condition on employee's performance, to realize the general satisfaction level of workers in the bank and study whether physical, social and psychological workplace influence job satisfaction. Discoveries of the examination demonstrated that the majority of the staff at the bank are happy with their workplace particularly the physical atmosphere. The paper infers that nature significantly affects representatives' satisfaction. The discoveries of the paper underline the requirement for the executives to improve the workplace of representatives to support productivity.

\section{Status}

Knowing one's employment status in a company also determines the presence or absence of job dissatisfaction among employees as it avoids uncertainty. From the analysis of results, it is seen that there is a significant difference between satisfaction and dissatisfaction with regards to status as a factor of motivation with $\mathrm{F}=5.276$ and with 17 responses to status associating it with dissatisfaction. Kang and Gould (2013) conducted a study so as to profile hospitality graduates' employment status and to determine the levels of overall job satisfaction of hospitality graduates. The outcomes portrayed by and large, respondents' job satisfaction from inside five measurements was moderate, extending from 3.51 to 5.10 on a 7-point Likert scale. Age and salary were huge elements influencing respondents' job satisfaction. The satisfaction level seems, by all accounts, to be most elevated among the respondents working between six to nine years in the business yet decays forcefully after that period.

\section{CONCLUSION}

Herzberg's theory has garnered both criticism and praise through generations. In this study, an attempt was made to apply Herzberg's principles to understand the employee motivation of the employees of IT sector of India. A sample of 35 respondents were used to conduct analysis on the hypothesis of motivation and hygiene factors. A quantitative methodology was adopted and data was collected through questionnaire method. The results depicted that among IT sector employees, there was a significant difference between satisfaction and 
dissatisfaction of job with regards to both motivation and hygiene factors, thereby, proving that the factors affecting satisfaction (motivating factors) differ from factors affecting dissatisfaction (hygiene factors). The overall results were in accordance with the theory proposed by Herzberg thereby, proving that even in today's times, such a historic theory holds merit.

\section{LIMITATIONS}

One of the limitations of the present study was that the sample was selected through convenience sampling and therefore, is not truly representative of the population. The sample size is low, heterogenous and therefore, the study can only be taken as an indicative. This makes it difficult to generalize the results to other industries and organizations. Another major limitation arises from the survey method used to collect data. Because the usefulness of the questionnaire is restricted to issues on which the respondents have more or less crystallized views that can be simply expressed in words. The questionnaire method does not allow for answers outside the given framework thus, squeezing the choice of options for the respondent. At the same time, the data collected was nominal in nature and therefore, doesn't allow to understand the strength or direction of the responses of the participants. Observing employee behaviour and interviewing employees can enable researchers to gain more insight that typically is difficult to acquire through this technique and thus identify the discrepancies between what is said and what is observed.

\section{IMPLICATIONS AND RECOMMENDATIONS}

The present study helps us understand the factors that contribute to work motivation and job satisfaction and the factors that lead to decreased work motivation and dissatisfaction with one's job. By identifying the best ways to enhance motivation of employees in one of the significant sector in terms of contribution to economy i.e. the IT sector, interventions can be planned to increase the overall satisfaction and motivation that would eventually contribute towards achieving the goals of the organization and thereby lead to personal as well as organizational growth.

Future research can be aimed at exploring work motivation and job satisfaction among employees in similar industries like telecommunication etc. in order to allow for a comparison to be made between employees belonging to different industries. Additionally, further research could also focus on comparing IT employees with non-IT employees and its implications. comparing job satisfaction levels of employees in several different IT organizations in India and what factors contributes to the differences in levels of satisfaction, if at all any exist. Such a comparison between various IT organizations would also help in understanding the organizational characteristics and behaviors that are unique to each organization. An attempt can also be made to understand what employees really want from their jobs. 


\section{QUESTIONNAIRE}

\section{PART I - GENERAL BACKGROUND INFORMATION}

For each of the following questions, please check the item corresponding to your status.

1. Please check one:
(a) Male
(b) Female

2. How old are you?
(a) Under 25
(b) $25-29$
(c) $30-39$
(d) $40-49$
(e) $50-55$
(f) Over 55

3. The highest level of your education:
(a) High School Graduate (b) Associate Degree
(c) Bachelor's Degree (d) Master's Degree or Above

4. How long have you been working in this bank?
(a) Under 3 months (b) 3 - 11 months
(c) 1 - 5 years $(\mathrm{d}) 6-10$ years
(e) Over 10 years

5.Have you received as many promotions as you expected during your career in this bank?
(a) None (b) One
(c) Two (d) More than Two

\section{PART II - SATISFACTION}

Please study the following statements and check all of the factors that caused you to feel strongly motivated and enthusiastic about your job which could have occurred on your present job or on other jobs you have held at this organization.

1. Seeing results of work.

2. Work praised. 
3. Idea accepted by company.

4. Received advancement.

5. Varied job.

6. Creative (challenging) job.

7. Opportunity to do a whole job--all phases.

8. Growth in skills, or in status (advancement).

9. Allowed to work without supervision.

10. Effective organization of work.

11. Beneficial personnel policies.

12. High company status.

13. Supervisor competent.

14. Supervisor delegated work well.

15. Friendly relations with supervisor.

16. Supervisor went to bat for you with management.

17. Supervisor willing to listen to suggestions.

18. Supervisor gave credit for work done.

19. Cooperation of people you worked with.

20. Liked people you worked with.

21. Good working relationship with subordinates.

22. Received wage increase.

23. Amount of salary.

24. Wages compare favorably with others doing similar or same job.

25. Tenure or other objective signs of job security.

26. Community and other outside situations.

27. Work in social surroundings.

28. Good physical surroundings.

29. Having a given status.

30. Other (Please specify)-

31. How strong was/is your feeling of satisfaction? (a) Low (b) Moderate (c) High

\section{PART III - DISSATISFACTION}

Please study the following statements and check all of the factors that caused you to feel dissatisfied about your job which could have occurred on your present job or on any other job you have held at this organization.

1. Not seeing results of work.

2. Work blamed or criticized.

3. Good idea(s) not accepted.

4. Failed to receive expected advancement.

5. Routine job.

6. Too easy job.

7. Too difficult job.

8. Lack of opportunity for growth. 
9. Lack of responsibility.

10. Harmful or ineffective organization of work.

11. Harmful personnel policies.

12. Low company status.

13. Supervisor incompetent.

14. Supervisor tried to do everything himself.

15. Unfriendly relations with supervisor

16. Supervisor did not support you with management.

17. Supervisor unwilling to listen to suggestions.

18. Supervisor withheld credit.

19. Lack of cooperation on the part of your co-workers.

20. Did not like people you work with.

21. Poor working relationship with subordinates.

22. Did not receive expected wage increase.

23. Amount of salary.

24. Wages compare unfavorably with others doing similar or same job.

25. Lack of objective signs of security (i.e., company --- instability).

26. Family problems.

27. Irregulated amount of work

28. Poor physical surroundings.

29. Not having a given status.

30. Other (Please specify)

31. How strong was/is your feeling of dissatisfaction? (a) Low (b) Moderate (c) High

\section{REFERENCES}

[1] Abioro, Matthew. (2013). Effect of employee motivation on organizational performance. Acta Gerencia Ciencia. 1. 17-27.

[2] Asproni, Giovanni. (2004). Motivation, teamwork, and agile development. [online] Researchgate.net. Available from https://www.researchgate.net/publication/229037802_Motivation_teamwork_and_agil e_development [12 April 2020]

[3] Aycan, Z. (2001) "Whatever Happened to Individual-level Studies of Work Motivation?", Cross-Cultural Psychology Bulletin 35(2): 7-13

[4] Campbell, J. and Pritchard, R. (1976) 'Motivation Theory in Industrial and Organizational Psychology', M. Dunette (ed.) Handbook of Industrial and Organizational Psychology. Chicago: Rand McNally.

[5] Gawel, Joseph E. (1996) "Herzberg's Theory of Motivation and Maslow's Hierarchy of Needs," Practical Assessment, Research, and Evaluation: Vol. 5, Article 11.

[6] Ghazi, S., Shahzada, G. and Khan, M. (2018). Resurrecting Herzberg's Two Factor Theory: an Implication to the University Teachers. [online] Mcser.org. Available from: http://www.mcser.org/journal/index.php/jesr/article/view/270 [Accessed 3 April 2020]

[7] Hackman, J. and Oldham, D. (1980) Work Design. Reading, MA: Addison-Wesley. 
[8] Herzberg, F., Mausner, B. and Snyderman, B. (1959) The Motivation to Work. New York: Wiley.

[9] Indian IT \& ITes Industry Report (February, 2020) Editorial. Indian Brand Equity Foundation [online] ibef.org. Available from https://www.ibef.org/industry/indian-iT-and-iTeS-industryanalysis-presentation [Accessed on 12 April 2020]

[10] Junior, Ivaldir \& Duarte, Luan \& Oliveira, Joao Paulo \& Dantas, Ari'dnes \& Barbosa, Jefferson \& Moura, Hermano. (2012). Motivational Factors for Distributed Software Development Teams. Proceedings - 2012 IEEE 7th International Conference on Global Software Engineering Workshops, ICGSEW 2012. 49-54. 10.1109/ICGSEW.2012.17. [online] Researchgate.net Available from: https://www.researchgate.net/publication/269032374_Motivational_Factors_for_Distributed_ Soft ware_Development_Teams/citation/download [Äccessed on 12 April 2020]

[11] Press Information Bureau, Government of India, Ministry of Electronics \& I (May 3, 2017), Employment Prospects in India's IT Sector: Robust Outlook

[12] Purohit, B. and Bandyopadhyay, T. (2014). Beyond job security and money: driving factors of motivation for government doctors in India. Human Resources for Health, 12(1).

[13] S. Zedeck, H. Aguinis, W. Cascio, M. Gelfand, K. Leung, S. Parker, J. Zhou, Handbook of industrial and organizational psychology (Vol. 3), Publisher: American Psychological Association, pp.223-248

[14] Sithiphand Chirarak. (1983). Testing employee motivation based on Herzberg's Motivationhygiene theory in selected Thai commercial banks. Unpublished PH.D.

[15] Thesis, Oklahoma State University

[16] Sanjeev, M. and Surya, A. (2016). Two Factor Theory of Motivation and Satisfaction: An Empirical Verification. Annals of Data Science, 3(2), pp.155-173.

[17] Teck-hong T., Waheed A., (2011). Herzberg's motivation-hygiene theory and job satisfaction in the Malaysian retail sector: the mediating effect of love of money. Asian Academy of Management Journal, Vol. 16, No. 1, 73-94

[18] Wan Yusoff W. F., Kian T. S., and Idris M. T. M., (2013), Herzberg's two factor theory on work motivation: does it work for today's environment?. Global Journal of Commerce and Management Perspective, 2(5). 